\title{
Identification of precipitation diurnal process using PERSIANN over Central Java Area
}

\author{
Muhammad Fianggoro ${ }^{1}$, Emilya Nurjani $^{1}$, and Andung Bayu Sekaranom ${ }^{1,2^{*}}$ \\ ${ }^{1}$ Department of Environmental Geography, Faculty of Geography, Universitas Gadjah Mada, Yogyakarta-Indonesia \\ ${ }^{2}$ Research Center for Disaster, Universitas Gadjah Mada, Yogyakarta-Indonesia
}

\begin{abstract}
The diurnal cycle is a process that repeats daily due to earth rotation. This cycle could significantly affect the hydrological conditions and lithosphere conditions, including humans. This diurnal cycle is also likely to influence seasonal patterns in the region. The diurnal cycle has a close relationship with the time-series pattern and distribution of rainfall. It often affects hydrometeorological disasters in the form of floods and droughts. This paper provides an overview of early identification related to the diurnal cycle of rain in the Central Java region - Indonesia. Rainfall estimation data from The Precipitation Estimation from Remotely Sensed Information using Artificial Neural Networks (PERSIANN) is used as the primary input in the analysis. The research results show that there are differences in rainfall patterns between the northern, central, and southern parts of the study area
\end{abstract}

\section{Introduction}

The diurnal cycle is a pattern that repeats itself every day for twenty-four hours [1]. This pattern is caused by the rotation of the earth on its rotating axis. The diurnal cycle is one of the most basic forms of meteorological patterns. The diurnal cycle is also considered a cycle on a local scale or a regional scale with a daily period [2]. The diurnal cycle is a daily cycle closely related to local climatic conditions. It has a mutual influence on climate phenomena that occur in an area, especially in the form of an archipelago [3].Temperature, humidity, and wind are the main drivers of the diurnal cycle, affecting rainfall. One of the parameters that are often influenced the diurnal cycles is wind, which includes land and sea breezes. These two types of wind have different characteristics and directions. In addition, characteristics of the nearby ocean potentially affect the amount of cloud formation and rainfall that propagate overland [4]. Although the rainfall pattern that occurs in the long term might be similar, it is possible to have different diurnal patterns. The distance between land and sea will also have implications for the distribution of rain and the characteristics of the diurnal cycle repetition.

Another parameter that is considered to affect the diurnal cycle is topography, where the shape or relief of the earth's surface also plays a role in regulating rainfall distribution [5]. The other variables that are considered significant are elevation and land use. The height of the surface of heterogeneous elevation for the central part of Java is allegedly contributing to the distribution of rainfall and influencing the diurnal cycle that occurs in the most central region of Java. The elevation parameter also has a direct relationship with temperature. Further, the direction to the slope has a relationship with meteorological parameters because it is related to humidity transport as carried by the wind. Apart from elevation, land use can directly or indirectly affect the diurnal cycle, mainly due to the urban heat island. The degree of fluctuation in land-use change dynamics can affect hydrological variables [6], which indirectly affects the repetition pattern of the diurnal cycle.

Central Java Region consists of Central Java and Yogyakarta Province, is flanked by two types of the sea with different characteristics, and provides a different tendency to study. The condition of the area, which has a dense population, encourages the need for precipitation-related analysis, particularly related to the disaster. The precipitation is closely related to the hydrological cycle, which is the main foundation for determining the potential of water resources and disasters. precipitation can affect the hydrological process over the land surface [7]. In this case, the diurnal cycle is an essential factor representing general meteorological conditions that recur in the two provinces. The diurnal cycle potentially influences the rainfall that occurs in Java, especially in the Central Java Region. At present, Central Java is mostly affected by hidrometeorological disasters, particularly floods. Diurnal cycle therefore is related to precipitation system that significantly affect the hydrological conditions and lithosphere conditions, including the local population. However, the understanding of the effects of this diurnal cycle is still not fully understood. There are a gap in the diurnal rainfall related research because most of the rainfall measurement is based on daily data.

\footnotetext{
* Corresponding author: andungbayu@geo.ugm.ac.id
} 
This paper contributes to the gap by using satellite estimation data to understand the process in detail. This diurnal cycle also has a significant possibility and influences the existing seasonal patterns in the region. Therefore, this paper aims to determine the diurnal cycle of rainfall in the Central Java region that particularly have implication to flooding.

\section{Data and method}

The diurnal pattern of rainfall can be measured by processing precipitation estimation data obtained from satellites orbiting above the earth's atmosphere [8,9]. This measurement provides rainfall estimation products in the area covered by the satellite's sensors. The satellite data used in this paper is data from the Center for Hydrometeorology and Remote Sensing (CHRS) at the University of California, Irvine (UCI). The product is Precipitation Estimation from Remotely Sensed Information Using Neural Networks (PERSIANN). In more detail, the product used is the PERSIANN-Cloud Classification System (PERSIAN-CCS) which has a spatial resolution of $0.04^{\circ} \times 0.04^{\circ}$ which, when converted in kilometers, are about $4 \mathrm{~km} \mathrm{x} 4 \mathrm{~km}$ over the tropics.

PERSIANN was developed with an artificial neural network to estimate the rain rate from Infrared (Infrared/IR) image data [10], with adjustment of network parameters based on the derived microwaves and ground measurement data. This product is able to estimate the level of precipitation around the world with coverage of $60^{\circ} \mathrm{S}$ to $60^{\circ} \mathrm{N}$. PERSIANN-CCS is the rainfall data estimate satellite output from CHRS with the highest resolution currently available and has been supported by an artificial neural network system that can process information more quickly and accurately $[11,12]$. The data available on the data access portal states that the PERSIAN-CCS rain data is available from January 2003 until the present. Rainfall data is available in the formation of different time intervals according to the needs of the analysis from hourly to daily.

The PERSIANN data was chosen because it has a reasonably detailed spatial resolution and has a temporal resolution of up to hours. Researchers and experts in Indonesia quite often use PERSIANN data as an instrument to estimate the value of rainfall in an area. Several studies using PERSIAN-CCS rainfall data include research conducted by [11] regarding the trend of extreme daily rainfall in the Bangka Belitung Islands. Another study conducted by Pratiwi et al. [13] used PERSIAN-CSS data to predict observational rain data using Cross-Correlation. Comparison of the PERSIANN-CCS data with surface measuring instrument data is known to produce minor differences. Thus, it is sufficient to represent the rainfall on the surface (14).

The diurnal cycle analysis of rainfall in this paper mainly uses the PERSIAN-CCS product. The data is downloaded on a predetermined temporal scale, namely in 2015 to 2019. The five years from 2015 to 2019 reflect the many global climate phenomena that affect the study area. Some examples of phenomena that influence the study area are El-Nino and La-Nina. The El-Nino phenomenon significantly affects land conditions on the island of Java. This climatic phenomenon often causes drought in Java and several other areas directly adjacent to the Indian Ocean and the Pacific Ocean. Another interesting phenomenon in the research data period is tropical cyclones, which occurred several times in the 2016-2019 period.

The analysis was carried out by making a spatial slice (cross-section) of rainfall statistics carried out on time composite data. This analysis aims to obtain the transverse rainfall profile of an area that was sliced. Another output that can be identified is the value of rainfall distribution according to the area being sliced. Determination of the cross-section is based on the variation in rain distribution and topographic conditions. In this case, it consists of one east-west section and one north-south section (Fig. 1). Because the data used consist of temporal dimension, this step will be repeated for each time variation resulting in the composite time information. The output is then analyzed descriptively by emphasizing other aspects that can support the argument regarding the rain distribution output.

The temporal resolution used is 1 hour which is then averaged every hour. Graphical representation is processed to identify the changes of each temporal variation of the rain data at each hour. The average rainfall data was carried out by overlaying the composite raster of the rain distribution obtained from the rainfall estimation product in the three-year temporal period at the same hour. The hourly mean data were then compared with the other hours in the same area. This output is then analyzed descriptively based on the pattern of extracted data.
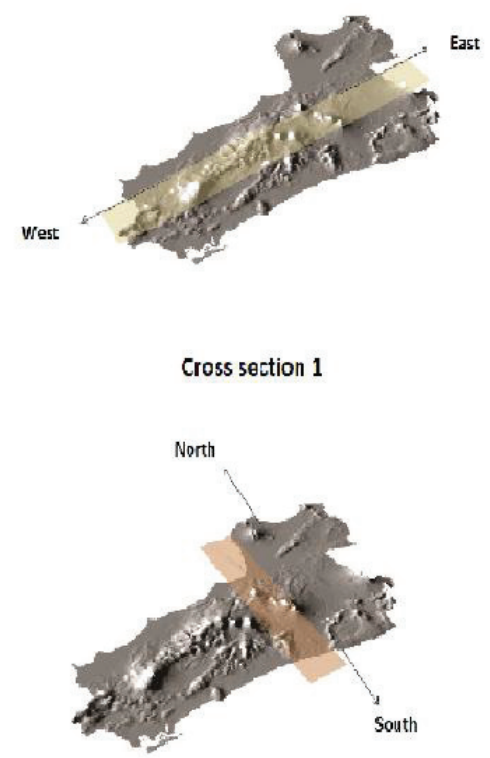

Cross section 2

Fig. 1. Cross sections for diurnal cycle analysis in the study area, including a) East-West, and b) North-South. (Source: Processing of elevation data from ETOPO:https://www.ngdc.noaa.gov/mgg/global/ 


\section{Result and discussion}

\subsection{Spatial distribution of precipitation}

As a maritime country, Indonesia is one of the regions in the world that has a high level of rainfall [15-17]. Java Island, especially the central part of Java, has variations in rainfall that are distinctly different each season. The central part of the island of Java is identified as having a monsoon type of rainfall. The data was taken from the central part of the island of Java on a five-year temporal scale starting from January 1, 2015, to December 31, 2019. The data obtained were then processed to obtain hourly rain data at the location. The hourly rainfall raster data is then combined based on the hour for five years to get the average hourly rainfall during the 2015-2019 period.

The results of the PERSIANN-CCS rainfall raster composite data were then shown every three hours to facilitate the identification of the diurnal cycle (Fig. 2). The results of the composite rainfall data for PERSIANCCS for five years showed several variations with quite clear differences. Judging from the spatial variation, periods with evenly distributed rainfall with a high enough intensity often occur at 12.00 and 15.00; for other hours, it is alleged that the distribution of rainfall is lower so that there is no rain at all.
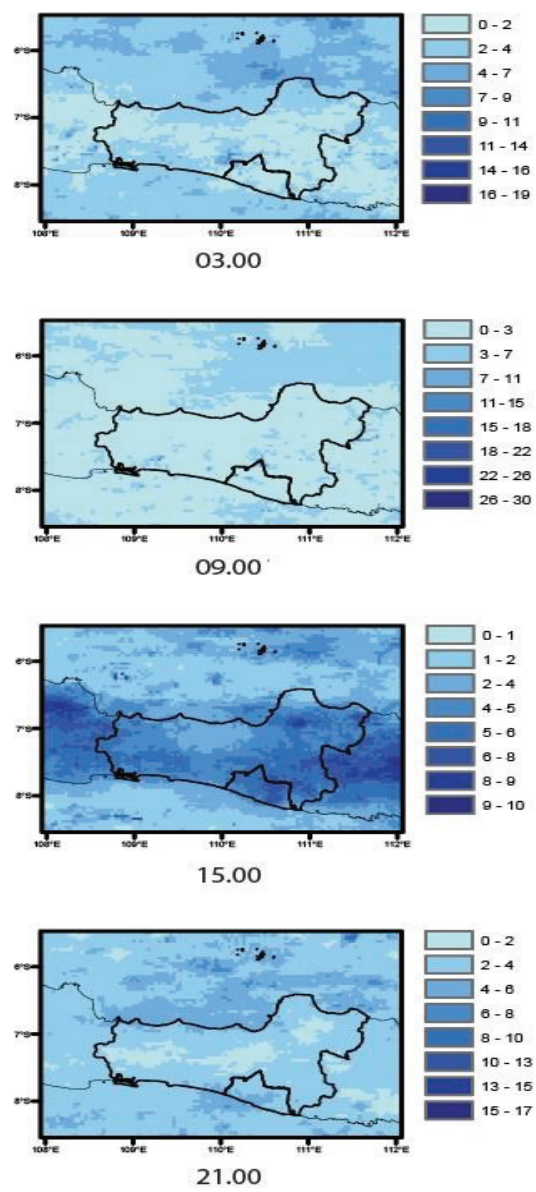

Fig. 2. Differences in the spatial pattern of average hourly rainfall (in $\mathrm{mm} / \mathrm{hr}$ ) at $3.00 \mathrm{a} . \mathrm{m}$. to $24.00 \mathrm{p} . \mathrm{m}$. local time during 2015-2019 (source: PERSIANN data processing) compile a cross-profile for the East-West and NorthSouth directions to facilitate the identification process of the diurnal cycle. The transverse profile is made as an initial analysis step that categorizes the temporal scale of rain before six-hour intervals, namely $06.00,12.00$, 18.00 , and 24.00 local times. This categorization is done to see the differences from the morning to midnight. The axis variables used are the length of the slicing area on the horizontal axis and the hourly rainfall value in millimeters per hour on the vertical axis.

\subsection{Cross Section Profile of Precipitation Rate}

Fig. 3 shows that the transverse profile of rainfall in the East-West direction shows the highest rainfall at 12.00 and 18.00 local time. The distribution of rain is relatively even in each region. At this location, the most frequent light rain occurs at noon. The low precipitation phases for this section are in the night at 24.00 p.m. until morning at $06.00 \mathrm{a} . \mathrm{m}$. During the last five years, rainfall in this area is indicated to have occurred frequently from noon to late in the evening. This shows the role of sea breezes that blow towards the land, which can bring rain clouds from the ocean and fall on the land. Meanwhile, land winds can bring back clouds and evaporation that occurs on land back to the oceans. It indicates that the diurnal pattern of land winds and sea breezes can regulate the cycle of rain occurring in the region.
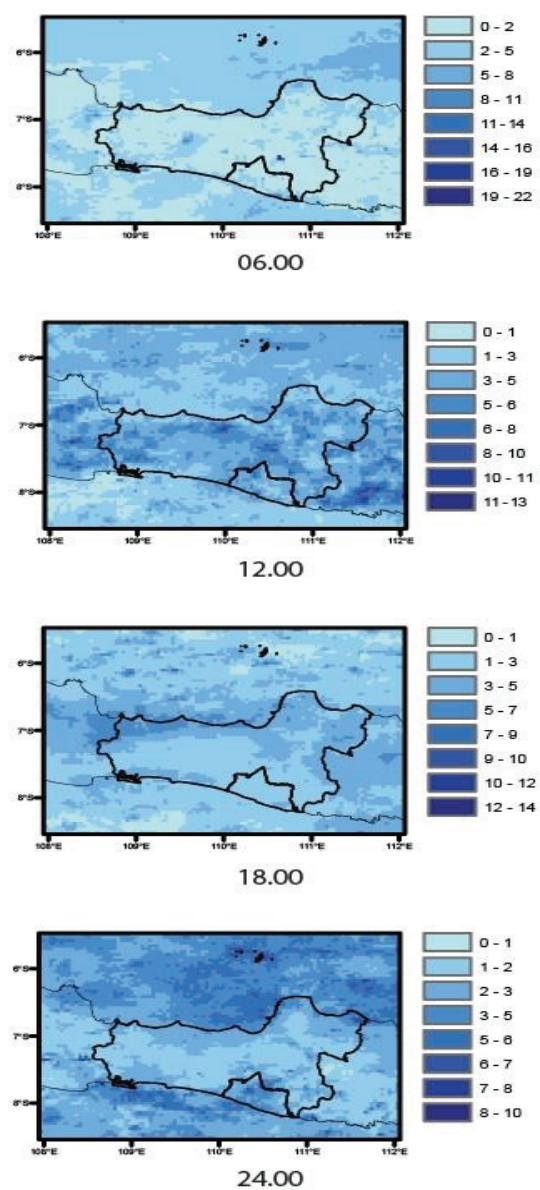

A slicing method was used for the study area to 


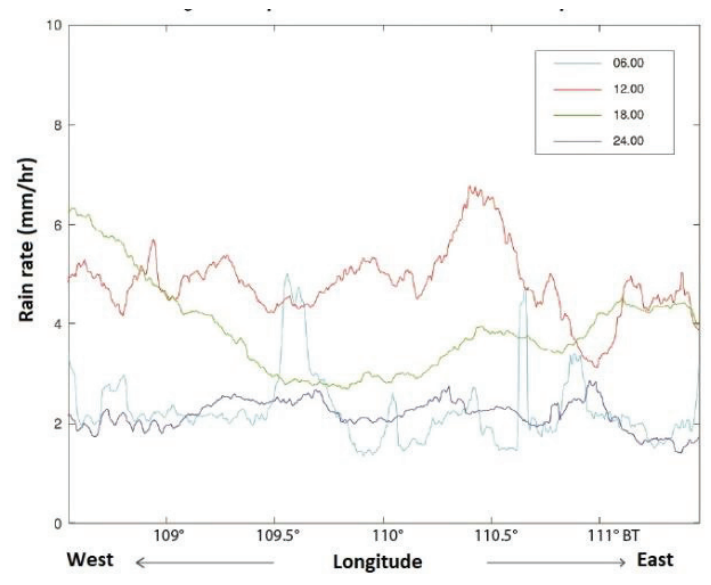

Fig. 3. Graph of the cross profile of average rainfall in eastwest direction (source: PERSIANN data processing)

The cross-sectional rainfall profile for the NorthSouth direction appears to have more fluctuations in the mean annual rainfall per hour (Fig. 4). This location intersects right between Mount Merbabu and Mount Merapi. The high elevation across the mountain can affect rainfall in intensity and peak rain time [4]. In terms of the average annual rainfall during 2015-2019, this location has moderate rain intensity with a value exceeding $6 \mathrm{~mm} /$ hour at 12.00 local time for areas around latitude $7^{\circ}$ to $7.5^{\circ} \mathrm{S}$. Based on the transverse profile, the lowest rain intensity occur at 18.00 local time for the $7^{\circ}$ to $8^{\circ} \mathrm{S}$. At this location, rain occurs more frequently in the afternoon to the night.

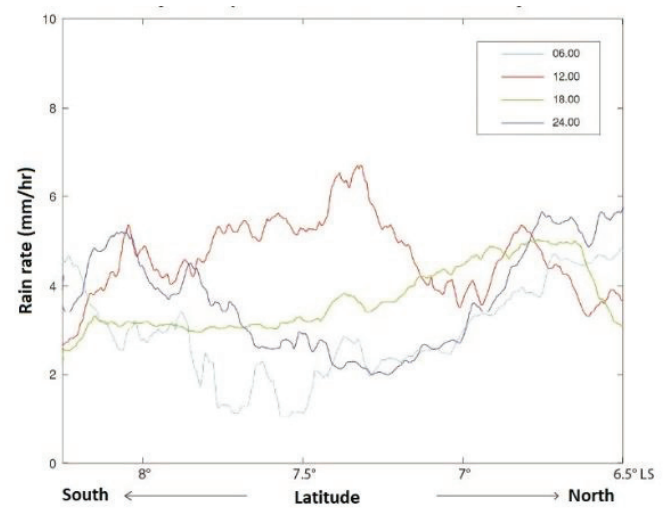

Fig. 4. Graph of the cross profile of average rainfall in northsouth direction (source: PERSIANN data processing)

The cross-sections of the east-west and north-south directions above show that the average rainfall conditions for the Central Java region have a diurnal pattern where the rain intensity moves up in the morning and has a moderate intensity in the afternoon. The rain intensity began to fall again from the afternoon and reached the lowest at night until the early hours. This phenomenon follows the diurnal pattern of land winds and sea breezes, which have the most significant role in bringing the humidity from the oceans in the north and south of the island of Java to the mainland in the morning to noon. In contrast, at night, the land winds bring back land circulation to the sea. At night, the land cools faster due to the loss of longwave radiation. At the same time, water remains warmer at night, so that the daily pressure pattern reverses, and land breeze forms as air moves to areas of lower pressure above the sea.

\section{Conclusion}

The above results show that over the study area, the spatial pattern of repetition of rain with an intensity of up to $7 \mathrm{~mm} /$ hour occurs between 10.00 a.m. to 3.00 p.m. Further, it is widely distributed in the central region of Java Island, especially in an area dominated by highlands and mountains. In the central part, the rain tends to be higher in the afternoon compared to the area close to the ocean. On the other hand, (in the southern and northern regions) rain occurs at a lower intensity than in the central part.

The diurnal cycle of rainfall shows that the intensity of the rain moves up in the morning and reaches moderate intensity in the afternoon. The intensity of the rain falls back down at night until early morning. This phenomenon is probably influenced by land and sea breezes, which have the most significant role in bringing the accumulation of clouds from the oceans in the north and south of Java to the mainland in the morning to noon. In contrast, at night, the land breeze brings back the circulation of the land to the sea. In regional content, the similar result are found in Sumatra and Borneo $[1,15]$. Therefore, high amount of late afternoon precipitation could potentially floods that occur among the country.

The next step suggested for related research is identifying factors that influence the cycle of repetition of rainfall in the region. Topography, which includes elevation, direction towards slopes, the distance of land to the coastline, and land use, has influenced rainfall patterns. The four topographic parameters mentioned have a role in changing the diurnal trend of rainfall on land, especially in the study area. Atmospheric factors, including meteorological parameters, predominantly temperature, humidity, wind direction, and speed, are also predicted to affect [18]. The analyzed meteorological parameters have a relationship with one another which significantly affects the distribution of rain both spatially and temporally

This publication is supported by grants of "Hibah Dosen Mandiri" by Faculty of Geography Universitas Gadjah Mada in 2021. The grant entitled "Modeling the Diurnal Process of Precipitation over Central Part of Java Island" is investigated by Dr. Andung Bayu Sekaranom and teams.

\section{References}

1. H. Ichikawa, T. Yasunari, J. Clim., 19, 1238-1260 (2006)

2. R. Ariani, The influence of the madden-julian oscillation on diurnal cycle of rainfall over sumatera. in Thesis, 1-54 (2014)

3. N.Suaydhi, Jurnal Sains Dirgantara, 14, 57 (2017)

4. A. Nanda, P. Septy, Characteristics of Diurnal Rainfall in Sangkapura-Bawean and Citeko-Bogor 
Meteorological Station based on regional and local influence. in Proceeding of Seminar Nasional Fisika Dan Aplikasinya, November 2015, Indonesia (2015)

5. D. Subarna, Seminar Sains Atmosfer, 1, 73-79 (2013)

6. M. Wibowo, Teknologi Lingkungan, 6, 283-290 (2005)

7. M. A.Solera-Garcia, N. A. Chappell, W. Tych, IAHS-AISH Publication, 308, 356-361 (2006)

8. A. B. Sekaranom, H. Masunaga, J. Appl. Meteorol. Climatol. 56, 1867-1881 (2017)

9. A. B. Sekaranom, H. Masunaga, J. Appl. Meteorol. Climatol., 58, 37-54 (2019)

10. R. R. E. Vernimmen, A. Hooijer, Mamenun, E. Aldrian, A. I. J. M.Van Dijk, Hydrology and Earth System Sciences, 16, 133-146 (2012)

11. A. Fadholi, Jurnal Ilmu dan Inovasi Fisika, 4, 1222 (2020)

12. A. B. Sekaranom, , E. Nurjani, M. P. Hadi, M. A. Marfai, Quaest. Geogr., 37, 97-114 (2018)
13. D. W. Pratiwi, J. Sujono, A. P. Rahardjo, Evaluation of satellite rainfall data for rain-rate estimation using cross correlation method, in Proceeding of Seminar Nasional Sains Dan Teknologi, 1-2 November 2017, Indonesia (2017)

14. Y. Hong, D. Gochis, J. T. Cheng, K. L. Hsu, S. Sorooshian, Journal of Hydrometeorology, 8 (3) (2007).

15. J.-H. Qian, J. Atmos. Sci., 65, 1428-1441 (2008)

16. A. B. Sekaranom, E. Nurjani, R. Harini, A. S. Muttaqin, Indonesian Journal of Geography, 52, 143-153 (2020)

17. A. B. Sekaranom, E. Nurjani, The development of Articulated Weather Generator model and its application in simulating future climate variability, in proceeding of IOP Conference Series: Earth and Environmental Science, 256 (2019)

18. A. B. Sekaranom, E. Nurjani, I. Pujiastuti, Cloud structure evolution of heavy rain events from the East-West Pacific Ocean: A combined global observation analysis, in proceeding of IOP Conference Series: Earth and Environmental Science, 148 (2018) 